\title{
AGÊNCIA DE PROPAGANDA: CASA DE ORATES OU TEMPLO DO ORÁCULO?
}

\section{Advertising agency: house of orates or oracular temple?}

\author{
Goiamérico Felício Carneiro dos Santos ${ }^{1}$
}

\begin{abstract}
Resumo
Diante das responsabilidades e dos compromissos que a sociedade midiática impõe, faz-se necessário repensar a percepção, os valores e os lugares que ocupam hoje as agências de propaganda. Assim, elas não poderiam estar no lugar de uma Casa de Orates: lugar de abrigo de lunáticos, sonhadores, inspirados, aptos a criar, instantaneamente, grandes sacadas, memoráveis campanhas e soluções mercadológicas em termos de comunicação? Se as agências têm por metas aconselhar, orientar, solucionar problemas dos seus clientes, não poderíamos inferir que essas se constituem em Templos do Oráculo, uma espécie de Santuário dos nossos tempos? Seriam os publicitários os novos Oráculos, aqueles que teriam as respostas para os problemas do mercado, das empresas, das instituições?
\end{abstract} Palavras-chave: agência de propaganda, casa de orates, templo do oráculo, cultura

\begin{abstract}
In the face of the responsibilities and compromises imposed by the media today, it is imperative do rethink the perception, the values and places occupied by advertisement in our society. In one sense ad agencies could be seen as a House of Orates: A home for lunatics, dreamers, inspired, and able to produce great ideas or marketing solutions instantly. If agencies, on the other hand, assume the role of counseling, orientation or problem solving for their clients, couldn't we interpret their role in terms of an Oracular Temple, a very special king of Sanctuary of our times? Are the adman the new Oracle? The one who holds the answer for the problems of the companies, the market, the institutions?
\end{abstract} Keywords: agencies of advertise, house of orates, oracular temple, culture

\section{Resumen}

Habida cuenta de las responsabilidades y compromisos que la sociedad impone a los medios

\footnotetext{
${ }^{1}$ Poeta, Mestre em Estudos da Linguagem, Doutor em Letras, Professor do curso de Publicidade e Propaganda e Coordenador do Programa de Pós-Graduação (stricto sensu) em Comunicação da Facomb- Faculdade de Comunicação e Biblioteconomia da UFG, onde integra a Linha de Pesquisa Mídia e Cultura; e-mail: goiamerico@uol.com.br.
} 
de comunicación, es necesario repensar la percepción, valores y los lugares que ocupan las agencias de publicidad hoy en día. Por lo tanto, estos tipos de empresas de comunicación no podrían estar en lugar de una Casa de Orates: un lugar de refugio para los locos, soñadores, inspirados, con capacidad de crear de forma instantánea mensajes memorables y soluciones de mercado en términos de comunicación? Si estos organismos tienen objetivos para el asesoramiento, orientación, resolución de los problemas de sus clientes, no podemos inferir que estos son los templos del Oráculo, una especie de santuario de nuestro tiempo? Serían los profisionales de la publicidad los nuevos oráculos, ó sea, aquellos que tienen las respuestas a los problemas del mercado, de las empresas, instituciones?

Palabras claves: agencia de publicidad, casa de orates, templo del oráculo, cultura

“A propaganda é a mais nova forma de arte do século 20"-M. MacLuhan

David Ogilvy, em Confissões de um publicitário, provocativamente, alude a uma situação que se vive nos bastidores das agências que bem pode soar como triste verdade para aqueles que estão diretamente no coração desse negócio chamado "indústria da propaganda" - o pessoal encarregado pelas estratégias de criação que, a partir de uma invenção de Bill Bernbach (o gênio criativo da lendária agência americana BBDO), passou a formar as denominadas duplas de criação que mais ou menos nos traz essa constatação: nas duplas de criação, temos um escritor frustrado frente a um artista plástico também frustrado.

Certamente, o mestre Ogilvy, ao mesmo tempo em que se refere ao fato de que a alma da propaganda é a criatividade, nos assevera que em publicidade e propaganda a criatividade não tem a mesma validade que tanto foi válida para os artistas parnasianos, que evocaram o direito de fazer "arte pela arte". Ou seja, no negócio da propaganda, a arte cada arte cada vez mais tem assumido a função poética ${ }^{2}$, em função de uma ideia, de uma estratégia de comunicação que deve colocar ao alcance do público-alvo os objetivos da campanha.

Mais precisamente, a arte deve estar a serviço da intencionalidade de marketing, deve ter uma funcionalidade, um objetivo de venda. Só que o poético deve comparecerem função de uma ideia mercadológica, em função de uma ideia, de uma estratégia de comunicação que deve colocar ao alcance do público-alvo os objetivos da campanha. Mais precisamente,

\footnotetext{
${ }^{2}$ Nas aulas de linguagem da propaganda e de criação publicitária, os alunos apreendem bem esse conceito "poético"quando do estudo das funções da linguagem. Cf. Roman Jakobson: Lingüística e comunicação. (1987) Ed. Cultrix
} 
a arte deve estar a serviço da intencionalidade de marketing, deve ter uma funcionalidade, um objetivo de venda.

Mas, venhamos e convenhamos: alguém ousaria admitir que quem não está direta e indiretamente envolvido com o negócio da propaganda (os publicitários, os estudantes de publicidade e o pessoal da área de marketing e comunicação da parte dos clientes e - quiçá! - os parentes mais próximos dos envolvidos) sabe o que é uma agência de propaganda, tem idéia dos papéis, das suas funções, dos seus comprometimentos e do grau de interesse e responsabilidade social e empresarial numa sociedade do consumo?

Com certeza, muitos publicitários já sofreram ou ainda sentem na carne o anátema da incompreensão e do preconceito oriundos até mesmo dos mais íntimos familiares e amigos e que por isso mesmo não raro são vítimas de sarcasmos e piadinhas? Não seria essa situação também um sintoma do quanto essa profissão foi e ainda vem sendo tão vilipendiada, tão maltratada, tão desrespeitada?

Não fosse apenas uma incapacidade para se dimensionar uma atividade profissional que agrega profissionais que, via de regra, devem ser preparados intelectual e tecnicamente, a par de um severo compromisso ético que visa a preservar a imagem, a lucratividade e a sustentabilidade, pra não dizer a própria existência de empresas, instituição e personalidades do mundo social, político e artístico, os publicitários ainda são ameaçados pelos simulacros de publicitários. Vide os "falsos publicitários" que, ainda hoje, assim se apresentam tãosomente pelo fato de que se arvoram a "publicistas" e "propagandistas"

No Brasil, propriamente falando, a instituição agência de propaganda tem uma história que, se pode dizer, é ainda relativamente recente. Foi sob o nome de Eclética Publicidade que, em 1914, tivemos o sucedâneo dos corretores de anúncios, profissionais que se encarregavam de vender espaços nos jornais. Esses corretores de anúncios ainda vicejam mesmo nos mercados das capitais brasileiras, mas têm forte atuação mesmo nos mercados periféricos. Os chamados pastinhas coletam os dados dos pequenos clientes, que não são dotados de uma cultura do marketing e tampouco têm uma noção do que venha a ser uma agência e muito menos dos múltiplos serviços que elas podem e devem prestar.

Ressalte-se que na Europa (Inglaterra, França e Alemanha) e nos Estados Unidos tivemos as organizações que compravam espaços por atacado nos veículos para revendê-los aos anunciantes que eram angariados. Como meras captadoras de anunciantes para os espaços vendidos, essas organizações não cumpriam papel maior que o de vendedoras de espaços dos veículos de comunicação.

\footnotetext{
${ }^{3}$ Os termos "publicista" e "propagandista" referem-se, consecutivamente, àqueles que fazem "propaganda de boca",em carros de som, "homens-sanduiche", distribuidores de flyers em ruas em semáforos e divulgadores de produtos delaboratórios farmacêuticos. Cf. RABAÇA, Gustavo. Dicionário de comunicação (1998), Ed. Campus e CAMPOS,Zander. Dicionário de Comunicação e marketing. (2007), Ed. Referência.
} 
Com isso, nem é preciso pensar muito para se chegar à conclusão de que as mesmas não tinham maiores compromissos com o processo. Ou seja, elas não se comprometiam com o processo de concepção das estratégias de comunicação (se é que se pensava naqueles tempos em estratégias), na elaboração das peças, nos efeitos que as mesmas deveriam produzir, nos resultados, enfim. Para resumo da ópera, esses protótipos de agências não estabeleciam vínculos profissionais mais estreitos com os anunciantes da hora e da vez que, em contrapartida, também não se compromissavam em manter a parceria para futuras ações, ou inserções de anúncios.

Mas verificou-se, não pouco tempo depois, uma tomada de consciência por parte desses modelos embrionários de agências. Sensibilizados com as promessas do negócio e também com os perigos de tais posturas, compreenderam os nossos publicitários precursores dos novos tempos que era preciso oferecer um pouco mais aos anunciantes para que os mesmos, como homens de negócios, pudessem sentir os benéficos efeitos das investidas em propaganda diretamente nos seus órgãos mais sensíveis - o bolso, ou o retorno no tilintar da caixa registradora de pagamentos.

Foi a partir dessas novas tomadas de consciência que as agências de propaganda emergiramse em meio ao mundo dos negócios com a firme disposição de mostrar a que vieram; para dar efetiva prova de que os fabricantes, os revendedores, os homens públicos dependiam dessas empresas para a garantia do crescimento e da própria sobrevivência na selva do mundo dos negócios repleta de predadores, onde somente os fortes, os que têm disposição para crescer se mantêm de pé.

Assim, ocorreram as especializações dentro das agências. Elas se encarregaram pela redação, pela ilustração, pela finalização e pelo acompanhamento da produção, da veiculação e da mensuração de resultados. Enfim, as agências passaram a estabelecer parcerias de negócios com as empresas-anunciantes cuidando de todo o processo de comunicação empresarial e mercadológica dos seus já então um pouco mais cativos clientes. Dizemos um pouco mais cativos clientes pelo fato de que a rotatividade, as perdas de clientes para as agências concorrentes são permanentes preocupações no meio.

Não é sem razão que o celebrado David Ogilvy, verdadeiro ícone da propaganda, em sua obra Confissões de um publicitário (1993) quase que num desabafo assim expressa a singularidade da profissão sempre ameaçada por todos os flancos: "A crise dos sete anos não é exclusividade dos casamentos. Ela aflige o relacionamento entre as agências de publicidade e seus clientes. O cliente muda de agência uma vez a cada sete anos. Ele cansa da sua agência, tanto quanto um gourmet enjoa do repertório de seu chef' (Ogilvy 1993).

Tal preocupação, que beira um verdadeiro estado de terror no meio, se dá pelo fato de que a perda de uma conta tende a gerar um efeito cascata, como bem assevera o mestre Ogilvy: 
Conquistar uma nova conta é uma experiência inebriante, mas perder uma conta é um inferno. O que fazer para convencer seus outros clientes de que eles não devem dispensá-lo? Vi duas agências entrarem em colapso de depois que a saída de um cliente provocou uma “corrida ao banco”. É um espetáculo deprimente. (Ogilvy 1993: 74)

Nesse mencionado capítulo "Como manter clientes", de suas Confissões..., no qual David Ogilvy, em tom professoral, reitera o verdadeiro flagelo que se vive na tarefa da administração uma agência, aludindo a duas exemplares profissões liberais, as classes dos médicos e dos advogados, que comparadas à profissão que exercem os publicitários podem significar verdadeiros paraísos no quesito stress. Vale a pena a citação.

\begin{abstract}
Se você aspira administrar uma agência, deve aceitar o fato de que estará sempre andando na borda de um precipício. Se você é um inseguro por natureza, uma pessoa assustadiça, ai de você! Estará metido numa dura jornada. Invejo meus amigos médicos. Eles têm tantos pacientes que a perda de um deles não os arruinará. Nem essa perda será noticiada nos jornais, para que todos os pacientes leiam. Também invejo os advogados. Eles podem tirar férias, seguros de que os outros advogados não estarão fazendo amor com seus clientes. Agora que construí um portfólio de dezenove excelentes clientes, desejaria que fosse aprovada uma lei tornando ilegal a solicitação pelas agências. Na Suécia, as grandes agências conquistaram uma lei desse tipo. Uma deliciosa restrição de mercado. (Ogilvy 1993: 74)
\end{abstract}

Vemos então, nesse processo de construção dos papéis a serem desempenhados pelas agências de publicidade, que, em pleno século XIX, quando germinou essa espécie de embrião daquilo que concebemos hoje como agência de publicidade, já tínhamos os primórdios dos tão discutidos bureaux de mídia, verdadeira ameaça aos modelos tradicionais de agência.

Essa concepção de agência de propaganda constitui-se em atividade profissional amparada pela Lei Federal no ${ }^{\circ} 4.680$, de 18/06/1965, regulamentada pelo Decreto 57.690 de 01/02/1966, que estabelece a concepção que deve nortear os ideais de uma empresa voltada ao ramo da propaganda. Ao pé-da-letra, eis o que diz a Lei 4.680:

\begin{abstract}
A Agência de Propaganda é pessoa jurídica especializada na arte e técnica publicitária que, através de especialistas, estuda, concebe, executa e distribui propaganda aos veículos de divulgação, por ordem e conta de clientes-anunciantes, com o objetivo de promover a venda de produtos e serviços, difundir idéias ou informar o público a respeito de organizações ou instituições colocadas a serviço deste mesmo público. (In: Conar - Código Brasileiro de Auto-Regulamentação Publicitária. Cf.: www.conar.org.br).
\end{abstract}

Digno de registro é o fato de que essa Lei anda sendo sobejamente desrespeitada, pra não dizer que anda mesmo em desuso. Eis uma triste e inegável constatação da qual não temos mais como fugir: não só a Lei 4.680, que estabelece a forma tradicional de remuneração - os famosos $20 \%$ de comissão de veiculação, mais $15 \%$ de verba de 
produção, além do BV (Bonificação de Volume de aplicação de verba no mesmo veículo) -, mas é o próprio modelo de agência que vem sendo ameaçada de existência.

Ou seja, é preciso que não só a forma de remuneração, mas a própria profissão, a atividade e o modelo de agência entrem na pauta de discussões por parte dos líderes e dos organismos representantes do negócio. Reitere-se que cada profissional, independente do seu nível de atuação, coloque esse impasse no rol de suas preocupações diárias. Isso porque o risco que se corre é o de ser ultrapassado, atropelado pelo processo histórico; ou seja, a palavra de ordem para se manter no negócio deve ser esta: mudar pra não morrer.

\section{AGÊNCIA DE PUBLICIDADE: CASA DE ORATES?}

Segundo a Paremiologia (Estudo das manifestações linguísticas), Casa de Orates carrega esse significado: Orate é o mesmo que louco, tendo chegado ao português através do espanhol orate, que vem do catalão orati, de uma forma do latim tardio ora ou oura.

Segundo J. P. Machado, orate veio do romance do latim aura, "ar, vento", que deu a forma portuguesa orate, e não os vocábulos indicados por Magalhães Jr. Ligando-se diretamente ao vocábulo oura, que significa "tontura de cabeça, vertigem". No Brasil, essa breve alegoria, Casa de Orates, ganhou a conotação de louco, idiota. Confira-se o prolóquio também como um ambiente de tumulto, desordem, balbúrdia. No Brasil, a expressão ganha popularidade através das tramas em que se enreda a personagem Simão Bacamarte, de "O alienista", narrativa em que Machado de Assis destila sua fina ironia em relação ao Positivismo e ao Cienticifismo que marcaram o início do século XX.

Portanto, os profissionais de propaganda, principalmente os "criativos" da agência, que assumirem a postura romântica de gênios criativos, intuitivos, correm o sério risco de se perderem. Lembremo-nos de que na era mítica, segundo a concepção platônica, o artista seria, no momento da criação, agente de um poder superior, perdendo o controle de si mesmo. Assim, as Musas, filhas de Apolo, desde a tradição homérica, eram invocadas em auxílio ao aedo na tarefa de narrar os feitos dos heróis. A criação, sob inspiração divina, seria capaz de inspirar e levar ao êxtase, tal como vimos na lenda de Orpheus, arquétipo do poeta, que encantava animais e homens com a divina doçura de sua lira. 
Contudo, os tempos que correm não mais permitem que prevaleça a concepção mítica de que a criatividade tem origem Divina. Os profissionais que persistirem no modelo tradicional de agência estarão se condenando ao cadafalso e jogando a própria profissão que abraçou na lata do lixo da história. Ou seja: buscar uma formação que venha a contemplar a habilidade de ser um "fazedor de anúncio" não tem nenhum sentido em uma atividade que tem por natureza estar na vanguarda das mudanças. Deve-se, definitivamente, estar imbuído permanentemente da noção de que a agência deve estar sempre "antenada" com os novos tempos. Enfim, todos aqueles que em qualquer nível hierárquico estiverem envolvidos com a atividade publicitária devem estar atentos às novas tendências da moda, aos novos usos de linguagem, às novas exigências tecnológicas, aos novos desafios empresariais, aos novos modus vivendi, sob pena de se colocar fora do jogo.

De natureza complexa, a atividade deve se fundamentar como um território livre para a criação, a experimentação, a inovação, a ousadia, para que as tendências que se avizinham sejam por ela antecipadas em favor dos clientes. Nesse sentido, nessa atividade deve prevalecer o princípio da ousadia precedida da necessária liberdade. Assim, não teria ainda hoje alguma pertinência este postulado de Lee Iacocca quanto a esse aspecto da liberdade na relação das agências com seus clientes?:

As relações agências-clientes devem ser bilaterais. Somente o cliente pode outorgar garantias de acesso, informação e persuasão, e somente quando a agência possui estas garantias é que pode contribuir de forma eficaz para o êxito do anunciante no mercado". (Sant'anna 2002: 251)

Em síntese, assim constituem-se "As quatro liberdades da publicidade”, instituídas por Iacocca (Sant'anna 2002: 251-258), que são essenciais para um frutífero relacionamento das agências com seus clientes e que devem se constituir em via mão dupla: liberdade de acesso à informação sobre o produto, o histórico da empresa, os estudos e os planejamentos de marketing; liberdade de participação no desenvolvimento das estratégias e nas pesquisas e testes dos produtos, para que a agência não seja acionada na última hora para desenvolver as estratégias de comunicação de algo que ela sabe por alto; liberdade de experimentar, no sentido de correr riscos, ousar, dispondo dos recursos com liberdade para propor algo que seja inusitado e pertinente; liberdade para convencer o cliente de que algo de errado tende a ocorrer, de que nem tudo está funcionando a contento, ou seja, liberdade para se contrapor ao chefe com ideias, soluções e sugestões alicerçadas em argumentos sólidos, convincentes. Afinal, conforme Iacocca, nenhuma agência é paga para simplesmente concordar com o cliente, assumindo os seus erros [deles, os clientes] como verdades sagradas. 
Talvez estejam aí, na ausência desse pacto das quatro liberdades, as raízes das quase sempre mal-sucedidas formações de house-agencies. O pessoal da house teria a mesma liberdade para se contrapor ao cliente que é literalmente o seu patrão? Também pode ser que o tão necessário "olhar de fora" do próprio umbigo, do próprio negócio seja obnubilado pelos limites impostos a quem trabalha com um só cliente ou uma só filosofia negocial.

Portanto, devemos reconhecer que são muitos os perigos que cercam a atividade publicitária. Por isso, é de bom alvitre uma agência se valer de estrutura organizacional composta por profissionais de sólida formação intelectual e também de muita informação atualizada, além de uma ampla capacidade de interagir com diferentes facetas do caldo cultural em que vive.

Espera-se que os egressos dos cursos de publicidade e propaganda sejam, como foi enfatizado antes, mais que um mero "fazedor de anúncio", mais que um publicitário. Será preciso que ele seja um profissional de comunicação persuasiva inteiramente, devotado ao mundo dos negócios.

Afinal esse profissional terá como missão diuturna criar e colocar em prática soluções em termos de comunicação para os problemas mercadológicos dos seus clientes. Por isso, espera-se daqueles que estão no ramo, ou que pretendem nesse mundo adentrar, que se constituam em profissionais full-time, completos em termos de formação cultural e completamente devotados à profissão e, principalmente, aos seus clientes, sempre tão ciosos de atenção e de antecipação na resolução dos seus problemas empresariais.

Por isso, o novo profissional de propaganda deve ser ao menos um pouco mais economista, um pouco mais administrador, um pouco mais artista, um pouco mais literato, um pouco mais psicólogo, enfim, um pouco mais completo que os profissionais que estão "mandando ver" no momento.

Até porque, a nova geração de publicitários universitários tem ainda a missão de provar ao mundo a que vieram; que os estudos teóricos em que se meteram durante o interregno de sua formação fazem a diferença em relação aos demais tão cheios de experiência de mercado. Eles devem também afastar o estigma que ronda a profissão, principalmente quando se é um criativo. Portanto, ainda hoje tem validade essa antiga preocupação quanto à percepção que obscurece o efetivo valor e compromisso de um o profissional de publicidade de propaganda: 
Quando se fala em publicitário forma-se mentalmente a imagem de um indivíduo com cabelos longos, roupas em cores berrantes. Isto pode ser um deles, mas não necessariamente. Apenas mais um homem. Nenhum gênio, se bem que muitos possam ser geniais. Essencialmente, o publicitário deve ter algo de psicológico, deve ter uma sólida base técnica, tem que conhecer os princípios da comunicação e saber as limitações que impõem os diferentes meios de Comunicação de Massa.

(Sant'anna 2002: 262)

Para alçarem-se a esses patamares da glória profissional os seus atores devem entender o papel social e ético que lhes cabe no contexto em que vivemos. Para isso, a atualização deve ser incessante. Essa seria a condição sine qua non para que qualquer um se estabeleça no mercado:

\footnotetext{
Além disso, é preciso acompanhar o novo ritmo dos negócios e entrar na Era da Informação. Estamos vivendo um novo período que começa a interferir profundamente na maneira das pessoas se relacionarem, se divertirem, se informarem e, por extensão, consumirem. Portanto, estão se estabelecendo novos preceitos mercadológicos, nichos oportunidades para profissionais de propaganda e marketing. (Sant'anna 2002: 262)
}

Como vemos, a publicidade constitui-se em importante instrumento de alavancagem do capitalismo, dando visibilidade e sustentação às vendas e às construções de imagens. Afinal, uma agência de publicidade - ainda que muitos clientes (principalmente dos mercados periféricos) façam ouvidos moucos para tal fato constitui-se como qualquer empresa que precisa ser regida por princípios administrativos sólidos, consistentes, tais como: diretrizes administrativas que preveem custos e lucros, sistema operacional, estrutura de pessoal e aparelhamento tecnológico, hierarquia e competência.

Posicionando-se como elemento fundamental nas atividades publicitárias, e por extensão no desenvolvimento estratégico das empresas e das instituições públicas, as agências têm um papel a desempenhar para o qual as qualidades técnicas e humanas são essenciais.

Mais do que um agente que faz a intermediação entre os clientes e os seus mercados, as agências de publicidade devem assumir o compromisso de transcender os papéis que delas, equivocadamente, os mais incautos esperam. Mais que funcionar como agente ativo nas relações de oferta e procura, as organizações de publicidade têm sustentação no mercado quando elas se especializam nas tarefas de análise de mercados e das culturas mais díspares. 
Valendo-se de tirocínio racional e também de uma considerável dose de sensibilidade para auscultar os valores, os desejos e os inconvenientes que perpassam o imaginário de um povo, os publicitários devem entender e, principalmente, gostar de gente. Não um gostar alheado, mas que seja exposto através de um profundo comprometimento ético na prática profissional; um compromisso em fazer uma comunicação que expresse os valores humanos que enobrecem o sentido de pertença ao mundo; e também expresse um comprometimento com o desenvolvimento sócioeconômico-cultural da sociedade em que se vive e também do mundo.

Tais requisitos nos remetem a uma feliz definição da natureza de uma agência de publicidade no contexto das empresas dotados do caráter de prestação de serviços: Agência de publicidade é definida como uma organização comercial independente, composta de técnicos e criadores, cujo objetivo é conceber, executar e controlar a publicidade e colocála nos veículos publicitários por conta das empresas que procuram encontrar clientes para seus bens e serviços. (Gomes 2003: 146)

Para tanto, as agências somente cumprirão fielmente os seus papéis caso estejam preparadas pessoal e tecnicamente para oferecer a cada cliente, como vemos em Gomes (2003), um leque de ações que vão desde o assessoramento em marketing, assumindo a tarefa de assessoramento em pesquisas, pré e pós-testes à participação em organização em eventos e demais ações específicas a cada atividade; a assessoria de imprensa (relação com os meios midiáticos) até, como é o esperado, o devido assessoramento em comunicação publicitária (planejamento, criação, produção e veiculação de campanhas e peças de promoção de vendas, RP e merchandising).

O fato é que a agência deve atuar conjuntamente com os respectivos departamentos do cliente ou, no caso de ausência e/ou inoperância do mesmo, assumir tais tarefas. Triste é reconhecermos esse panorama em que a agência deve assumir um papel que deveria ser do cliente, qual seja, o de estabelecer a sua política de marketing e de comunicação.

Assim, imbuída de responsabilidades de tal monte, não estaria na condição de uma Casa de Orates. Uma casa que estaria abrigando uns lunáticos, sonhadores, permanentemente com a cabeça nas nuvens. Ao contrário, as agências de publicidade poderiam se aliar às empresas e às instituições sociais prestando a elas os relevantes serviços que conferem ao negócio da propaganda o adjetivo de "indústria da propaganda" e que com tamanho status ornamenta os seus mais bem sucedidos profissionais.

\section{AGÊNCIA DE PUBLICIDADE: TEMPLO DO ORÁCULO?}


Por outro lado, sabemos que uma agência de publicidade tem por princípio aconselhar, orientar, dar sentidos aos seus clientes em busca da superação de seus problemas de mercado, em busca da superação de seus limites e, por conseguinte, da própria sobrevivência. Sendo assim, não poderíamos inferir que as agências não constituiriam uma espécie de santuário dos nossos tempos? Um lugar especial onde se vai consultar os novos oráculos, os publicitários, que teriam as respostas dos deuses do mercado para os empecilhos humanos, das empresas, das instituições?

Lembremos que, na Grécia arcaica, os oráculos tinham como missão dar respostas dos deuses às perguntas que inquietavam os homens. Todo aquele desejoso de conhecer o futuro, que sentia a necessidade de conhecer a realidade que o cercava, ou que estava em busca do autoconhecimento recorria aos oráculos. Esses homens sequiosos de verdade recorriam àqueles que faziam o religare (a ligação) com as potestades divinas, fazendo as devidas consultas em busca das palavras reveladoras da verdade que possibilitaria o desvio dos erros em suas condutas como cidadãos exemplares que deveriam ser da Pólis. Dessa forma, o futuro coadunado pela conduta réproba, pelas boas ações, seria garantido a que tivesse a prudência de, através dos sacrifícios e das oferendas, receber os benefícios das revelações.

Salientemos ainda que toda empresa, para ser bem sucedida e que precisa superar os adversários (a concorrência e a apatia dos consumidores); toda empresa que se sente ameaçada, que se encontra sob a ameaça da crise, deve procurar uma agência em busca dos bons conselhos. Nelas estarão os novos oráculos ou os novos retóricos dotados de um discurso persuasivo capaz de encantar o público-alvo e, por conseguinte, capaz de garantir do futuro das empresas e dos bons negócios.

\section{CULTURA - VIDA OU MORTE DAS AGÊNCIAS}

Diante desse quadro esboçado pelos principais líderes que constituem a plêiade daqueles que ajudaram a colocar a propaganda brasileira no patamar das mais louvadas em todo o mundo pela natureza criativa de suas produções; diante dos iminentes desafios, verdadeiros "trabalhos de Hércules", que os publicitários têm que cotidianamente enfrentar em nome da sobrevivência, que caminhos devem ser trilhados? Não seria uma busca pela afirmação de uma cultura própria, que estabeleça nitidamente o posicionamento das agências frente ao mundo dos negócios, frente à própria vida, a maneira para se conquistar um crescimento contínuo e duradouro? 
Para sustentar seus argumentos, que preconizam a necessidade de as agências de publicidade delimitarem, ainda que não consciente e expositivamente, as suas culturas empresariais, John Philip Jones considera que esse tipo de atividade, comparada com as outras atividades empresariais, que constituem as suas carteiras de clientes, tem uma natureza peculiar. Jones retoma essa pertinente ponderação de Sir David Orr, um proeminente homem do mundo do marketing, à guisa de reforçar o seu argumento em relação à diferença cultural entre agências e seus clientes. As atividades de uma agência:

se desenvolve dentro de uma cultura diferente... empresas que fabricam produtos, sejam eles mercadorias ou serviços, são sempre mais estruturadas e hierárquicas... e têm profundo conhecimento sobre seus produtos ou serviços, ao passo que a agência é mais sensível às tendências mais amplas do mercado. (Orr apud Jones 2002: 145)

Para Philip Jones a cultura de uma agência - cultura essa que pode ser visível em suas apregoadas estratégias, comportamentos, posicionamentos e princípios éticos (nem sempre verbalizados) - constitui-se em fator muito importante para a estabilidade e a produtividade de uma agência que assim pode garantir a rentabilidade de seus esforços para promover o crescimento saudável de seus clientes e de si próprias.

Em seu esforço para esclarecer melhor a peculiaridade do sentido de cultura numa estrutura empresarial voltada às atividades da publicidade, Philip Jones (2002: 145) nos brinda com essa dupla distinção de cultura:

Na minha própria experiência com agências de publicidade, a cultura em si
(independentemente das influências externas e internas que sofre) tem duas dimensões
separadas: o tipo de pessoa que a agência contrata (a cultura social) e a atitude da agência
em relação ao empreendimento da publicidade (a cultura filosófica). Essas coisas nem
sempre são articuladas, embora isso já tenha acontecido em alguns casos individuais bem
conhecidos.

Nesse estudo de Philip Jones podemos ter um vislumbre mais avaliativo e crítico do perfil das agências que se constituíram no mercado para aprender com seus erros e seus acertos. O professor do Royal Melbourne Institute of Tecnology nos faz lembrar que:

A cultura social define o estilo, senso de valores, princípios éticos, clima da agência e seu posicionamento na comunidade de negócios, bem como as normas de comportamento (declaradas ou não-declaradas) que a agência espera de seus empregados. Isso inclui a definição que a agência dá ao atendimento ao cliente, do qual um importante aspecto é: se a agência está ou não preparada para, ocasionalmente, dar um conselho objetivo, mas difícil de engolir. (Jones 2002:147)

Lembrando que a cultura de uma agência de publicidade vai sendo construída, arraigada, aos poucos, às vezes de uma forma não programática, pelos seus líderes. Aliás, 
existe um tipo de compensação para que o pessoal mais qualificado da agência não entre na rotatividade, tão comum no meio, que é o chamado salário emocional. Mas a cultura corporativa nunca pode ser imposta de cima para baixo. A liderança é exercida em um ambiente de estrita colaboração entre os mais graduados e os subordinados. Esse espírito de corpo único possivelmente vem a ser um dos fatores que possibilitam a disseminação do ambiente em que a cultura da agência viceja.

A cultura corporativa de agência mais interessante, segundo Jones, é a da Leo Burnett, que está direcionada para se fortificar na criação, sem que a pesquisa seja deixada de lado. Afinal, a criação, mesmo se realizando muito mais através do feeling, da heurística (euriskein - tentativa, em grego), não pode abrir mão do componente do algoritmo, ligado às ciências exatas. É aí que entra a pesquisa, que vai direcionar, dar os rumos para a elaboração das estratégias de criação.

Conclui-se assim que, além de compreender duas facetas da cultura, a social e a filosófica, as agências tendem a mostrar ser fortes para a conta - centrando todos os esforços no atendimento ao cliente - ou para a criação, quando o corpo de colaboradores se ampara mais nas mentes criativas, voltadas mais para o sensível, o artístico e as ousadias em suas estratégias discursivas. Qualquer agência que não se posicionar numa dessas vertentes de cultura certamente terá sempre o vislumbre de uma ameaça à sua sobrevivência.

Não será, portanto, com a loucura e os desatinos de um Orates, mas com os dotes de um Oráculo de dialogar com o mercado, entender profundamente a cultura, os desejos, e os inconvenientes dessa vida moderna que os publicitários conseguirão dar as precisas respostas que deles esperam os clientes e os consumidores.

“Tudo na TV é como se fosse uma dieta de baixas calorias, então não adianta reclamar dos comerciais - eles, pelo menos, fazem os programas parecerem melhores do que são"

J. Baudrillard

\section{REFERÊNCIAS BIBLIOGRÁFICAS}

ACCIOLY, Anna [et alli]. Marcas de valor no mercado Brasileiro. Rio de Janeiro: Senac, 2000.

BRANCO, Renato Castelo [et alli], (Planej. E Coordenação). História da Propaganda no Brasil. São Paulo: T. A. Queiroz Editora, 1990.

CAPPO, Joe. O futuro da propaganda: nova mídia, novos clientes, novos consumidores na 
era pós-televisão. São Paulo: Cultrix/Meio\&Mensagem, 2005.

CARRASCOZA, João Anzanelo. A evolução do texto publicitário. 4a. ed. São Paulo: Futura, 2003.

. Redação publicitária. 4a . ed. São Paulo: Futura, 2003.

. Razão e sensibilidade no texto publicitário. São Paulo: Futura, 2004.

Do caos à criação publicitária. São Paulo: Saraiva, 2008.

DE MAIS, Domenico. Criatividade e grupos criativos - V. 1. Trad. Léa Manzi e Yadyr Figueiredo. Rio de Janeiro: Sexante, 2003.

Criatividade e grupos criativos - V. 2 (Fantasia e concretude). Trad. Léa Manzi e Yadyr Figueiredo. Rio de Janeiro: Sexante, 2005.

DUAILIBI, Roberto \& SIMONSEN JR., Harry. Criatividade \& Marketing. São Paulo: McGraw-Hill, 1990.

JOANNIS, Henri. O processo de criação publicitária: estratégia, concepção e realização de mensagens publicitárias. 2a. ed. Trad. Isabel Maria St. Aubyn. Portugal: Edições CETOP/Portugal, 1998.

JOHNSON, Paul. Os criadores. Trad. Ana Beatriz Rodrigues. Ri

GALVÃO, Pedro. [org.]. Nossos últimos 20 anos. (História da agência Galvão \& Associados - Belém/PA). São Paulo: Escrituras, 2003.

GOMES, Neusa Demartini. Publicidade: comunicação persuasiva. Porto Alegre: Sulina, 2003.

GRACIOSO, Francisco \& PENTEADO, José Roberto Whiteaker. Cinqüenta anos de vida e propaganda brasileiras. São Paulo: Mauro Ivan Marketing Editorial, 2001.

JONES, John Philip. A publicidade como negócio [org.]. Tradução de Lúcia Helena Sant`Agostino [et alli]. São Paulo: Nobel, 2002.

A publicidade na construção das grandes marcas [org.]. Tradução de Elizabeth Chammas. São Paulo: Nobel, 2004.

LAW, Andy. Empresa criativa: como a St. Luke`s pode transformar o seu trabalho. Tradução de Juliana Geve Lacerda. São Paulo: Negócio, 2001.

MAYER, Martin. Afinal, o que aconteceu (e o que acontecerá) com a Madson Avenue?. Tradução de Alice Bittencourt e Tânia Posselt. Porto Alegre: Ortiz/Gazeta Mercantil, 1991.

MARCONDES, Pyr. Uma história da propaganda brasileira. Rio de janeiro: Ediouro, 2001 .

PENTEADO, José Roberto Whiteaker. A propaganda antiga. São Paulo: Livraria Editora Pioneira, 19874. 
Agência de propaganda: casa de orates ou templo do oráculo?

de Goiamérico Felício Carneiro dos Santos

PEREZ, Clotilde \& BARBOSA, Ivan Santo [orgs]. Hiper-publicidade: fundamentos e interfaces - V 1. São Paulo: Thomson Lerning, 2007.

\&___. [orgs]. Hiper-publicidade: atividades e tendências - V 2. São Paulo:

Thomson Lerning, 2007.

RAMOS, Ricardo. Do reclame à comunicação: pequena história da propaganda no Brasil. São Paulo: Atual, 1985.

RIES, Al \& RIES, Laura. A queda da propaganda: da mídia paga à mídia espontânea. Tradução de Ana Beatriz Rodrigues. São Paulo: Campus, 2002.

SANT`ANNA, Armando. Propaganda: teoria - técnica - prática. $7^{\mathrm{a}}$ ed. [rev. e atualizada]. São Paulo: Pioneira/Thomson Learning, 2002.

ZYMAN, Sergio. A propaganda que funciona: como obter resultados com estratégias eficazes. Tradução de Fábio Fernandes. São Paulo: Campus, 2003.

ZEFF, Robbin \& ARONSON, Brad. Publicidade na internet. São Paulo: Campus, 2000.

Artigo recebido em 10/7/2009.

Aprovado em 23/8/2009. 